\title{
Investigation of the relationship between hemogram parameters and procalcitonin levels in patients with psychiatric diseases
}

\author{
Kader Semra Karatas ${ }^{1}$, Burcu Kilicgedigi², Tahsin Gokhan Telatar ${ }^{3}$, Ilkay Bahceci ${ }^{4}$, Bulent Bahceci², \\ Cicek Hocaoglu² \\ 'Psychiatry Department, School of Medicine, Kütahya Health Sciences University, Kütahya, Turkey \\ ${ }^{2}$ Psychiatry Department, School of Medicine, Recep Tayyip Erdogan University, Rize, Turkey \\ ${ }^{3}$ Public Health Department, School of Medicine, Recep Tayyip Erdogan University, Rize, Turkey \\ ${ }^{4}$ Microbiology Department, School of Medicine, Recep Tayyip Erdogan University, Rize, Turkey
}

Neuropsychiatria i Neuropsychologia 2021; 16, 3-4: 147-154

\author{
Address for correspondence: \\ Kader Semra Karatas, Assist. Prof. \\ Psychiatry Department \\ School of Medicine \\ Kütahya Health Sciences University \\ Kütahya, Turkey \\ e-mail: drsemraidil@gmail.com
}

\section{Abstract}

Introduction: This study aimed to evaluate the relationship between the hemogram parameters and the levels of procalcitonin, serum C-reactive protein, and inflammation in inpatients with psychiatric disorders.

Material and methods: The study population consisted of 549 inpatients treated between January 2018 and December 2020. Data were obtained retrospectively from computer records and inpatient files. Only the first hospitalization of each patient was evaluated, and 199 patients were included in the study. The researchers examined the parameters including platelet activation, neutrophil lymphocyte ratio, monocyte lymphocyte ratio, platelet count, mean platelet volume, platelet distribution width, platelet lymphocyte ratio, and procalcitonin levels in patients and compared them with findings obtained from a control group.

Results: Increased levels of C-reactive protein and decreased levels of platelets were observed in patients with schizophrenia, bipolar disorder, depressive disorder, and anxiety disorder. Increased platelet distribution width, platelet lymphocyte ratio, and neutrophil lymphocyte ratio were observed in patients with schizophrenia. The patients with bipolar disorder had increased mean platelet volume while patients with depressive disorder had an increased monocyte lymphocyte ratio. Procalcitonin levels increased in patients with anxiety disorder and depressive disorder.

Discussion: Platelet activity can be an important criterion to investigate the etiopathogenesis underlying the inflammatory process in schizophrenia, bipolar disorder, depressive disorder, and anxiety disorders. To our knowledge, this is the first study to describe a positive correlation between increased monocyte lymphocyte ratio and procalcitonin levels in depressive disorder, and a positive correlation between increased procalcitonin levels and anxiety disorder and depressive disorder.

Key words: platelet activity, procalcitonin, psychiatric disorders.

\section{Introduction}

Psychiatric diseases such as schizophrenia, bipolar disorder (BD), depressive disorder (DD), and anxiety disorder are severe mental disorders that affect millions of people worldwide. Differences in clinical characteristics and severity of the diseases, recurrence of disorders, different treatment methods, and chronic courses suggest that many factors are involved in the etiopathogenesis of these diseases (McGrath et al.
2008; Grande et al. 2016; Vandeleur et al. 2017; Stein et al. 2017). Previous studies have suggested that neurotransmitter systems, hormones, neurotrophic factors, and inflammatory and immune systems are effective in the etiopathogenesis of these disorders. Recent studies indicate that inflammatory mediators play an important role in modulating the proinflammatory process (Miller et al. 2011; Ng et al. 2018; Smaga et al. 2015). 
The increased expression of inflammatory cytokines such as interleukin (IL)-1 $1 \beta$, IL-6, and transforming growth factor $\beta$ (TGF- $\beta$ ) observed during an acute relapse of a psychiatric disorder decreases after treatment with antipsychotics; however, the expression levels of some cytokines such as IL-12, interferon $\gamma($ IFN- $\gamma$ ), tumor necrosis factor $\alpha$ (TNF- $\alpha$ ) do not change despite antipsychotic treatment. The levels of these cytokines were examined in patients with schizophrenia and their relatives (Miller $e t$ al. 2011). A previous study also investigated the effects of inflammatory mediators on acute phase proteins such as $\alpha 1$ antitrypsin, haptoglobin, and $\mathrm{C}$-reactive protein (CRP) in patients with schizophrenia (Ng et al. 2018; Smaga et al. 2015). The psychopathological condition of some patients improved after treatment with nonsteroidal antiinflammatory drugs (Moody and Miller 2018). The neutrophil, monocyte, and platelet counts may be altered in patients with schizophrenia, and patients having these counts within normal limits show a better response to treatment (Mazza et al. 2019). White blood cells such as leukocytes, neutrophils, and monocytes are involved in the inflammatory process underlying the etiopathogenesis of psychiatric diseases such as anxiety disorders and obsessive-compulsive disorder (OCD); thus, white blood cells have been used as biological markers in diagnosis and treatment of these diseases (Karataş et al. 2020; Gurok et al. 2019). However, the white blood cell counts obtained using a hemogram can be affected by many factors, and studies on systemic inflammation indicate that neutrophil lymphocyte ratio (NLR), platelet lymphocyte ratio (PLR), and monocyte lymphocyte ratio (MLR), which are least affected by confounding factors, are more accurate determinants of the presence of psychiatric diseases (Mazza et al. 2019; Balta et al. 2013). The NLR, PLR, and MLR increased not only in patients with schizophrenia but also in patients with $\mathrm{BD}, \mathrm{DD}$, and OCD (Mazza et al. 2019; Sunbul et al. 2016; Kirlioglu et al. 2019; Karatas et al. 2021). Some studies have reported no relationship between NLR and the severity of the psychiatric disease (Moody and Miller 2018; Semiz et al. 2014). Furthermore, PLR and MLR are associated with the prognosis of patients with schizophrenia (Mazza et al. 2019; Özdin et al. 2017).

Previous studies have examined the relationship between changes in red blood cells observed using a hemogram and chronic psychiatric disease (Wysokiński and Szczepocka 2018; Hochman et al. 2014). Patients with DD showed all three types of anemia, namely, microcytic anemia, macrocytic anemia, and normocytic anemia, and the hemograms of most patients showed a decrease in red blood cells (Wysokiński and Szczepocka 2018). The mean corpuscular volume (MCV) and mean corpuscular hemoglobin $(\mathrm{MCH})$ levels increased in patients with $\mathrm{BD}$ and decreased in patients with schizophrenia (Wysokiński and Szczepocka 2018; Hochman et al. 2014).

Recent studies showed that changes in platelet (PLT) activity are associated with the prognosis of chronic psychiatric diseases rather than changes in white and red blood cells (Karatas et al. 2021; Wysokiński and Szczepocka 2018; Hochman et al. 2014). Results of previous studies showed that parameters such as mean platelet volume (MPV) and platelet distribution width (PDW), which are indicators of PLT activation during inflammation, were associated with disease and disease severity in schizophrenia, BD, DD, and OCD; however, the results did not establish a clear correlation between these factors and the psychiatric disorders (Ng et al. 2018; Karataş et al. 2020; Karatas et al. 2021).

Recent studies have found a significant relationship between procalcitonin (PCT) levels and inflammation in patients with DD and schizophrenia (Barbosa et al. 2013; Varun et al. 2018). PCT is a hormone released from thyroid C cells, leukocytes, and neuronal cells, and almost all the PCT secreted is converted to calcitonin under normal conditions (Barbosa $e t$ al. 2013; Walker 2015; Matwiyoff et al. 2012). However, IL-1 $\beta$ and TNF-alpha released from macrophages and bacterial components during the inflammatory process inhibit the conversion of PCT to calcitonin, thereby increasing the levels of calcitonin in the blood (Walker 2015; Matwiyoff et al. 2012). PCT levels increase with an increase in CRP levels, particularly in severe systemic diseases such as inflammatory bowel diseases, respiratory system diseases, sepsis, and immunological diseases such as lupus and rheumatoid arthritis (Shehabi et al. 2014; Buhaescu et al. 2010). High levels of PCT are observed in patients with schizophrenia and bipolar mania who did not use medication (Barbosa et al. 2013; Varun et al. 2018; Miller et al. 2014). However, no studies have examined the levels of PCT as an inflammatory marker in other psychiatric diseases such as DD and anxiety disorder.

Thus, this study aimed to address this gap in the literature by examining the levels of various parameters using a hemogram. A limited number of studies have examined all hemo- 
gram parameters, particularly NLR, PLR, MLR, PLT activation, and PCT levels simultaneously in patients with different psychiatric diseases. These values are believed to be good indicators of the disease and can be obtained easily using an inexpensive method. Thus, these parameters should be included in the evaluations of the disease and the severity of the disease. Therefore, this study evaluated the hemogram parameters and CRP values of inpatients with psychiatric disorders and compared them with those from a control group. The results of this study may provide important insights for future research on mental disorders.

\section{Material and methods}

\section{Study design}

This was a descriptive epidemiological study.

\section{Population, sample, and data collection}

The population of this study consisted of 549 female inpatients, who were treated at the Recep Tayyip Erdoğan University Training and Research Hospital Psychiatry Clinic between January 2018 and December 2020. Male patients were not included in the study because the clinic provided services only to female patients. Only the first hospitalization of each patient was included in the evaluation. The data were obtained retrospectively from computer records and inpatient files. A total of 199 patients diagnosed with a psychiatric disease as schizophrenia (46 patients), anxiety disorders (42 patients), bipolar disorders (48 patients), or depressive disorder (63 patients) according to the diagnostic criteria specified in the Diagnostic and Statistical Manual of Mental Disorders, fifth edition (DSM-5), who had no systemic diseases such as heart, kidney, neurological, or autoimmune disease, and who had no physical or cognitive problem that prevents communication, were included in the study.

Participants who did not receive regular antipsychotic, antidepressant, anxiolytic, and mood stabilizer treatment in the last 3 months were included in the study, although the treatment was arranged earlier.

All patients with psychiatric disorders were administered the Brief Psychiatric Rating Scale at the beginning of their hospitalization. Patients with schizophrenia were followed up with the Brief Psychiatric Rating Scale.

Patients with bipolar disorder were followed up with the Young Mania Rating Scale.
Patients with anxiety disorders were followed up with the Hamilton Anxiety Rating.

Patients with depressive disorder were followed up with the Hamilton Depression Rating Scale.

Patients younger than 18 years and older than 65 years, who had any systemic disease such as heart, kidney, neurological, or autoimmune disease, and who received immunosuppressive therapy in the last 6 months, were excluded from the study.

The participants in the control group were selected among the female employees working at the hospital. Objective evaluation of these participants was performed by a psychiatrist who was not involved in the data collection and evaluation phase of the study. The participants who did not have any psychiatric illnesses detected and autoimmune, neurological, physical, or systemic disorders, and previous history of treatment with immunosuppressive or antipsychotic agents, and who agreed to participate in the study were included in the control group.

\section{Data collection tools}

The researchers examined the patient files, evaluated the sociodemographic data and the data obtained from the Brief Psychiatric Rating Scale (BPRS), the Young Mania Rating Scale (YMRS), the Hamilton Anxiety Rating Scale (HAM-A), and the Hamilton Depression Rating Scale (HAM-D) used for clinical monitoring and follow-up according to the diagnosis group. They evaluated the CRP levels and hemogram parameters to investigate the etiology of the disease and to determine the medical condition of the patients on the first day of hospitalization.

\section{Sociodemographic form}

The form was prepared by relevant experts using the patient files and information in the routinely completed inpatient follow-up files. The form included questions about the age, marital status, educational status, and employment status of the participants.

\section{Brief Psychiatric Rating Scale}

The BPRS was developed to evaluate the severity of the disease and consists of 18 questions. It provides information about anxiety, depression, thought disorder, aggression, and agitation in psychiatric diseases. 


\section{Young Mania Rating Scale}

The YMRS consists of 11 items each with five degrees of severity. Cronbach's $\alpha$ was used to determine the internal reliability of the scale items, and two independent researchers reported the Cronbach's $\alpha$ as .79. The correlations of the scale items with the total score ranged from .342 to .817 , except for the items of sleep, appearance, and insight. It was adapted for use in the Turkish population (Karadağ et al. 2001).

\section{Hamilton Anxiety Rating (HAM-A) Scale}

The HAM-A was developed by Hamilton to determine the level of anxiety and distribution of symptoms in patients. It consists of 14 items and can be used to assess both somatic and psychic symptoms. The responses on the HAM-A were similar to those obtained using a 5-point Likert-type scale. The total score on the HAM-A was the sum of the points obtained on each item. The Turkish validity and reliability study of this scale was conducted by Yazic1 et al. (Aydemir and Köroğlu 2012).

\section{Hamilton Depression Rating Scale}

The HAM-D administered by clinicians measures the level of depression and the change in the severity of disease in patients. It consists of structured questions, and the responses are scored between 0 and 4 . The scores are evaluated as follows: $0-13$ as no depression; 14-27 as mild depression; 28-41 as moderate depression; and $42-53$ as severe depression. It was developed by Hamilton and Williams and was adapted for use in the Turkish population by Akdemir et al. (1996) (Aydemir and Köroğlu 2012).

\section{Statistical analysis}

The frequencies of continuous data were expressed as median and interquartile range. The distribution characteristics of continuous variables were determined using Shapiro-Wilk and Kolmogorov-Smirnov tests. The Mann-Whitney $U$ test and Kruskal-Wallis test were used to evaluate the relationships between variables. The inflammatory parameters were compared among groups by the generalized linear model. The sensitivity and specificity values were determined for variables showing statistical significance. The statistical significance level was accepted as $p<0.05$ for all analyses.

\section{Ethics committee approval}

Local ethics committee approval was obtained from the Recep Tayyip Erdogan University Faculty of Medicine Non-Interventional Clinical Research Ethics Committee with the number 2020/207 and dated October 16, 2020. All applications in this study were made following the ethical standards of the institutional and/ or national research committee and the 1964 Declaration of Helsinki and its subsequent revisions, or comparable ethical standards.

\section{Results}

No significant difference was observed in the sociodemographic data between the control and patient groups (Table 1 ).

The levels of CRP and PLT were significantly different in all disease groups in the comparison of the blood values of patients with schizophrenia, anxiety disorder, BD, and DD with the control group $(p \leq 0.000, p \leq 0.000$, $p \leq 0.000$, and $p \leq 0.000$ vs. $p \leq 0.002, p \leq 0.000$,

Table 1. Sociodemographic data of the participants

\begin{tabular}{|c|c|c|c|c|c|c|c|c|c|c|c|}
\hline \multirow[t]{2}{*}{ Variable } & \multicolumn{2}{|c|}{$\begin{array}{l}\text { Control } \\
(n=113)\end{array}$} & \multicolumn{2}{|c|}{$\begin{array}{c}\text { Schizophrenia } \\
(n=46)\end{array}$} & \multicolumn{2}{|c|}{$\begin{array}{l}\text { Anxiety disorders } \\
(n=42)\end{array}$} & \multicolumn{2}{|c|}{$\begin{array}{l}\text { Bipolar disorder } \\
\quad(n=48)\end{array}$} & \multicolumn{2}{|c|}{$\begin{array}{l}\text { Depressive disorder } \\
\qquad(n=63)\end{array}$} & \multirow[t]{2}{*}{$p$} \\
\hline & $n$ & $\%$ & $n$ & $\%$ & $n$ & $\%$ & $n$ & $\%$ & $n$ & $\%$ & \\
\hline Age* $^{*}$ & 32.9 & 9.2 & 44.8 & 12.8 & 41.4 & 14.8 & 41.6 & 13.5 & 44.5 & 14.8 & $0.141^{* *}$ \\
\hline Marital status & & & & & & & & & & & 0.102 \\
\hline Married & 61 & 54.0 & 21 & 45.7 & 30 & 71.4 & 31 & 64.6 & 38 & 60.3 & \\
\hline Single & 52 & 46.0 & 25 & 54.3 & 12 & 28.6 & 17 & 35.4 & 25 & 39.7 & \\
\hline $\begin{array}{l}\text { Employment } \\
\text { status }\end{array}$ & & & & & & & & & & & 0.121 \\
\hline Employed & 66 & 58.4 & 6 & 13.0 & 11 & 26.2 & 16 & 33.3 & 13 & 20.6 & \\
\hline Unemployed & 47 & 41.6 & 40 & 87.0 & 31 & 73.8 & 32 & 66.7 & 50 & 79.4 & \\
\hline
\end{tabular}

*Means and standard deviations

${ }^{\star *}$ Analyzed using the Kruskal-Wallis test; $\chi^{2}$ test was used in other analyses 
$p \leq 0.007, p \leq 0.003)$. A significant difference was observed in the MPV ( $p \leq 0.025)$ between the control and the BD group. Moreover, significant differences were observed in the PDW, PLR, and NLR ( $p \leq 0.044, p \leq 0.008$, and $p \leq 0.003)$ in the schizophrenia group while a significant difference was observed in the MLR $(p \leq 0.023)$ in the DD group. A significant difference was observed in the hemoglobin $(\mathrm{Hb})$ and hematocrit (Hct) levels in patients in all disease groups compared to the control group. Similarly, a significant difference was observed in the MCV and $\mathrm{MCH}$ levels in patients in the schizophrenia $(p \leq 0.001$ and $p \leq 0.002)$ and $\mathrm{BD}$ groups $(p \leq 0.000$ and $p \leq 0.001)$ compared to the control group. A significant difference was observed in the PCT levels between the control group and the anxiety disorder and DD groups $(p \leq 0.005$ and $p \leq 0.035$ (Table 2).

\section{Discussion}

The results of this study showed that CRP levels increased and PLT levels decreased in patients with schizophrenia, BD, DD, and anxiety disorder.

The study found that the PDW, PLR, and NLR increased in the schizophrenia group, MPV increased in the BD group, and MLR increased in the DD group. While a decrease in $\mathrm{Hb}$ and Hct levels was observed in all disease groups, the schizophrenia and BD groups had increased $\mathrm{MCV}$ and $\mathrm{MCH}$ levels. Additionally, an increase in PCT levels was observed in the patients with anxiety disorder and DD.

CRP levels were examined in previous studies on the inflammatory etiopathogenesis underlying chronic psychiatric diseases; however, consistent results were not obtained in these studies (Sunbul et al. 2016; Karataş et al. 2020; Karatas et al. 2021; Danner et al. 2003; Kalia and Silva 2015; Wium-Andersen $e t$ al. 2013). Increased CRP levels are observed in patients with schizophrenia, DD, BD, generalized anxiety disorder, and OCD (Karataş et al. 2020; Kalia and Silva 2015; Frasure-Smith et al. 2007). Some studies indicate that CRP levels increased independently, especially in patients with DD (Sunbul et al. 2016; Kalia and Silva 2015; Pasko et al. 2010), whereas other studies indicate that there is no change in CRP levels (Bankier et al. 2008). The results of this study showed that the CRP levels of patients with psychiatric diseases increased, which indicates the importance of measuring

Table 2. Comparison of the values obtained using a hemogram between the disease group and the control group

\begin{tabular}{|c|c|c|c|c|c|c|c|c|c|}
\hline & $\begin{array}{l}\text { Control } \\
(n=113)\end{array}$ & $\begin{array}{l}\text { Schizophrenia } \\
\quad(n=46)\end{array}$ & $p$ & $\begin{array}{l}\text { Anxiety } \\
\text { disorders } \\
(n=42)\end{array}$ & $p$ & $\begin{array}{l}\text { Bipolar } \\
\text { disorder } \\
(n=48)\end{array}$ & $p$ & $\begin{array}{c}\text { Depressive } \\
\text { disorder } \\
(n=63)\end{array}$ & $p$ \\
\hline CRP & $0.1(0.3)$ & $2.48(3.93)$ & 0.000 & $1.85(4.5)$ & 0.000 & $1.92(4.08)$ & 0.000 & $2.31(5.09)$ & 0.000 \\
\hline WBC & 7770 (1355) & 7790 (2982.5) & 0.455 & 7295 (3247.5) & 0.062 & 7215 (3187.5) & 0.224 & $7080(2925)$ & 0.217 \\
\hline $\mathrm{HCT}$ & $39.3(2.35)$ & $39.45(4.53)$ & 0.018 & $37.95(5.53)$ & 0.001 & 38.45 (3.58) & 0.001 & $38.95(5.48)$ & 0.012 \\
\hline $\mathrm{HB}$ & $13(0.75)$ & $12.85(1.35)$ & 0.021 & $12.8(1.78)$ & 0.021 & $12.65(1.45)$ & 0.001 & $12.95(1.90)$ & 0.001 \\
\hline MCV & $86.8(8)$ & $89.85(7.03)$ & 0.001 & $88.55(6.27)$ & 0.131 & $90.55(6.7)$ & 0.000 & $86.90(7.55)$ & 0.630 \\
\hline $\mathrm{MCH}$ & $28.8(3.3)$ & $29.7(2.65)$ & 0.001 & $29.55(3.33)$ & 0.258 & $29.75(2.65)$ & 0.001 & $29.20(3.05)$ & 0.188 \\
\hline $\mathrm{MCHC}$ & $32.7(1.4)$ & $33(1.2)$ & 0.816 & 33.1 (1.6) & 0.601 & $32.9(0.98)$ & 0.853 & 33.10 (1.33) & 0.276 \\
\hline PLT & 294 (123) & 308.5 (102.5) & 0.002 & $247.5(79.25)$ & 0.000 & $258.5(96.75)$ & 0.005 & $260.00(78.75)$ & 0.003 \\
\hline MPV & $9.4(0.8)$ & $9.6(1.33)$ & 0.553 & $9.7(1.65)$ & 0.170 & 9.85 (1.58) & 0.037 & $9.55(1.30)$ & 0.152 \\
\hline PCT & $0.26(0.1)$ & $0.3(0.12)$ & 0.231 & $0.24(0.06)$ & 0.003 & $0.26(0.09)$ & 0.227 & $0.25(0.07)$ & 0.028 \\
\hline PDW & $16(0.6)$ & $15.8(0.5)$ & 0.036 & $16(0.53)$ & 0.962 & $16.05(0.58)$ & 0.386 & $16.00(0.42)$ & 0.784 \\
\hline RDW-SD & $41.3(6.35)$ & $43.25(4.58)$ & 0.650 & 42.6 (3.28) & 0.475 & $43.9(5.45)$ & 0.193 & $41.75(5.15)$ & 0.659 \\
\hline RDW-CV & $13.2(5.3)$ & $13.3(1.68)$ & 0.490 & $13.15(1.53)$ & 0.296 & $13.4(1.05)$ & 0.559 & 13.35 (1.65) & 0.916 \\
\hline NLR & $2.05(1.56)$ & $2.58(2.04)$ & 0.002 & $2.12(2)$ & 0.123 & $2.16(1.33)$ & 0.145 & $1.94(1.03)$ & 0.745 \\
\hline PLR & $123.4(90.19)$ & $152.64(74.87)$ & 0.007 & $124.97(80.29)$ & 0.473 & $132.03(68.3)$ & 0.760 & $121.32(71.26)$ & 0.218 \\
\hline$M L R$ & $0.22(0.15)$ & $0.22(0.14)$ & 0.155 & $0.19(0.1)$ & 0.444 & $0.22(0.11)$ & 0.741 & $0.18(0.07)$ & 0.019 \\
\hline
\end{tabular}

CRP - C-reactive protein; WBC - white blood cells; HCT - hematocrit; HB - hemoglobin; MCV - mean corpuscular volume; $M C H$ - mean corpuscular hemoglobin; PLT - platelets; MPV - mean platelet volume; PCT - procalcitonin; PDW - platelet distribution width; RDW-SD - red cell distribution width - standard deviation; RDW-CV - red cell distribution width - coefficient of variation; NLR - neutrophil lymphocyte ratio; $P L R$ - platelet lymphocyte ratio; $M L R$ - monocyte lymphocyte ratio

Generalized linear model was used for comparison and age was included as a covariate. 
CRP levels for investigating the etiopathogenesis of inflammation in psychiatric diseases.

Previous studies indicate that stress induces a release of cytokines and enzymes from PLT, which decreases the PLT count. Moreover, the MPV, PDW, and apoptosis may increase, thereby contributing to inflammation (Camacho and Dimsdale 2000; Tzura et al. 2019; Asoglu et al. 2016). The change in PLT activity in psychiatric diseases can be used as a peripheral marker and may be associated with mortality in these patients (Karatas et al. 2021; Camacho and Dimsdale 2000; Asoglu et al. 2016). PLT count decreases in patients with schizophrenia (37). Some studies reported that there were changes in PLT serotonin levels in patients with mood disorders, and these levels may be used as a marker for increased cardiovascular mortality, especially in patients with DD (Camacho and Dimsdale 2000). The PLT count decreases and PDW increases in patients with OCD (Karatas et al. 2021). Increased MPV in patients with BD has been associated with inflammation (Mert and Terzi 2016). The results of this study showed that the changes in the levels of various markers showing PLT activity in all disease groups support the inflammatory etiopathogenesis and that PLT activity may be a useful marker of prognosis; thus, it should be monitored in patients with psychiatric diseases.

Recent studies have investigated the PLR (Mazza et al. 2019; Balta et al. 2013), which is affected least by external factors, and have evaluated it together with NLR as another inflammatory and prognostic marker (39). NLR and PLR levels are associated with the severity of disease in patients with schizophrenia, BD, DD, and OCD (Mazza et al. 2019; Karatas et al. 2021; Kulaksizoglu and Kulaksizoglu 2016). The NLR and PLR were high in patients with schizophrenia (Moody and Miller 2018; Kulaksizoglu and Kulaksizoglu 2016). In addition, recent studies show that monocyte counts and MLR obtained using a hemogram are prominent markers of inflammation in psychiatric diseases (Karatas et al. 2021). Monocyte activation may be a marker of inflammation in patients with DD (Sunbul et al. 2016). Furthermore, monocyte count increased in patients with BP, DD, and schizophrenia (Mazza et al. 2019). It had been reported that the MLR increased in patients diagnosed with OCD for the first time, which supports the inflammatory etiopathogenesis of this disease and may be used in determining the disease severity (Karatas et al. 2021). The results of this study indicate that increased MLR levels in patients with DD may be an important marker in studies on the etiopathogenesis of psychiatric diseases. The study results showed that parameters such as NLR, PLR, and MLR are associated with schizophrenia and DD. These parameters can be easily determined during a routine examination and can be obtained using an inexpensive method such as a hemogram.

Anemia is very common in patients with chronic psychiatric diseases (Wysokinski and Szczepocka 2018). Previous studies reported that anemia was more common in patients with schizophrenia than patients with other psychiatric diseases, which was associated with increased mortality (Wysokiński and Szczepocka 2018; Barshtein et al. 2004). Some studies have emphasized the relationship between disease severity and the degree of anemia in patients with DD (Karataş et al. 2020; Alves de Rezende et al. 2019). Macrocytic anemia is frequently reported in patients with BD (Wysokiński and Szczepocka 2018); however, some studies reported a decrease in the $\mathrm{Hb}$ and $\mathrm{Hct}$ levels during the bipolar manic period and an increase in these levels during the depressive period (Hochman et al. 2014). Similarly, the results of this study showed that there was a decrease in $\mathrm{Hb}$ and Hct levels in all disease groups, and an increase in MCV and $\mathrm{MCH}$ levels in the patients with schizophrenia and BD. An advantage of this study is that it was conducted on patients with different psychiatric diseases; thus, hematological data from these patients could be compared. However, whether the changes in blood parameters play a role in the etiopathogenesis or whether chronic psychiatric diseases cause anemia has yet to be clearly explained.

Studies on the etiopathogenesis underlying the inflammatory process in psychiatric diseases showed that PCT levels increased in schizophrenia patients and that PCT is a more sensitive marker than CRP (Buhaescu et al. 2010; Miller et al. 2014). Barbosa et al. reported that there was an increase in PCT levels in two out of $10(14 \%)$ patients with BD who were in the manic period, but no change was reported in patients in the euthymic period, which was interpreted as the inability of low-grade inflammation to significantly affect PCT levels in patients with BD (Aydemir and Köroğlu 2012). Another study reported that PCT levels of patients with BD increased (Mert and Terzi 2016).

A previous study found that PCT levels did not increase in patients with schizophrenia who were taking any antipsychotic medication and treatment doses were equaled with mean (stan- 
dard deviation) $383.1 \mathrm{mg}$ cholorpromazine. The study's explanation for the absence of increased levels of PCT levels in chronic schizophrenia is that most cytokines capable of modulating the transcription process of PCT tend to normalize according to the chronicity of the disease and the use of antipsychotics (de Campos et al. 2015).

Another inflammatory etiopathogenesis study showed that the PCT levels were significantly higher in patients with schizophrenia who did not take medication than in those in the control group (Buhaescu et al. 2010).

In our study, it is important to note that PCT is affected in patients with chronic psychiatric disease who have not received regular treatment for the last 3 months.

As stated in the previous study, although PCT is thought to be affected in schizophrenia patients with regular antipsychotic use and duration of illness, the larger sample size indicates that controlled and prospective studies are needed in patients diagnosed for the first time.

We found that increased PCT levels were associated with the disease in patients with anxiety disorder and DD, which supports the inflammatory etiopathogenesis of the diseases. Another advantage of this study is that increased PCT levels were reported in patients with different psychiatric diseases such as anxiety disorder and $\mathrm{DD}$ for the first time besides schizophrenia and BD.

\section{Limitations}

This study had certain limitations: 1 . The most important limitation was that it did not include any male patients because only female patients were followed up in the inpatient service. 2. A smaller number of patients met the inclusion criteria; therefore, this study had a small sample size. 3. Since this was a retrospective, clinical follow-up study, only the available tests in patient follow-ups were evaluated. 4. Also, only BPRS was used in the clinical follow-up of patients with schizophrenia, and the Positive and Negative Syndrome Scale was not used. 5. The duration of illness was not recorded in the file scans.

\section{Conclusions}

A positive correlation was observed between decreasing PLT counts and schizophrenia, BD, $\mathrm{DD}$, and anxiety disorder. Significant differences in PLR of schizophrenia patients and MPV of BD patients were found, and this result suggests that PLT activity can be used as a parameter in schizophrenia, BD, DD, and anxiety disorder. There is a relationship between the increase in MLR and PCT values in patients with DD, and the increase in PCT levels in anxiety disorder and the diseases. To our knowledge, this is the first study to report these observations in patients with psychiatric diseases.

\section{Disclosure}

The authors declare no conflict of interest.

\section{References}

1. Akdemir A, Örsel S, Dağ i, et al. Hamilton depresyon derecelendirme ölçeği (HDDÖ)'nin geçerliliği, güvenirliliği ve klinikte kullanımı. Psikiyatri Psikoloji Psikofarmakoloji Dergisi 1996; 4: 251-259.

2. Alves de Rezende CH, Coelho LM, Oliveira LM, PenhaSilva N. Dependence of the geriatric depression scores on age, nutritional status, and haematologic variables in elderly institutionalized patients. J Nutr Health Aging 2009; 13: 617-621.

3. Asoglu M, Aslan M, Imre O, et al. Mean platelet volüme and red cell distribution width levels in initial evaluation of panic disorder. Neuropsychiatr Dis Treat 2016; 12: 2435-2438.

4. Aydemir Ö, Köroğlu E (Eds.). Psikiyatride Kullanılan Klinik Ölçekler. 6. Baskı.: Hekimler Yayın Birliği, Ankara 2012; 33-657.

5. Balta S, Demirkol S, Unlu M, et al. Neutrophil to lymphocyte ratio may be predict of mortality in all conditions. $\mathrm{Br}$ J Cancer 2013; 109: 3125-3126.

6. Bankier B, Barajas J, Martinez-Rumayor A, Januzzi JL. Association between C-reactive protein and generalized anxiety disorder in stable coronary heart disease patients. Eur Heart I 2008; 29: 2212-2217.

7. Barbosa IG, Rocha NP, Huebra L, et al. Not all inflammatory biomarkers are elavated in Bipolar Disorder: Evidence for procalcitonin. Biol Psychiatry 2013; 74: 29-30.

8. Barshtein G, Ponizovsky AM, Nechamkin Y, et al. Aggregability of red blood cells of schizophrenia patients with negative syndrome is selectively enhanced. Schizophr Bull 2004; 30: 913-922.

9. Buhaescu I, Yood RA, Izzedine H. Serum procalcitonin in systemic autoimmune diseases - where are we now? Semin Arthritis Rheum 2010; 40: 176-183.

10. CamachoA, DimsdaleJE.Plateletsandpsychiatry:lessons learned from old and new studies. Psychosom Med 2000; 62: 326-336.

11. Danner M, KasI SV, Abramson JL, Vaccarino V. Association between depression and elevated C-reactive protein. Psychosom Med 2003; 65: 347-356.

12. de Campos SM, Barbosa IG, Ribeiro-Santos R, et al. Procalcitonin levels in schizophrenic patients and patients with sepsis. Schizophr Res 2015; 168: 575-576.

13. Frasure-Smith N, Lesperance F, Irwin MR, et al. Depression, C-reactive protein and two-year major adverse cardiac events in men after acute coronary syndromes. Biol Psychiatry 2007; 62: 302-308.

14. Grande I, Berk M, Birmaher B, Vieta E. Bipolar disorder. Lancet 2016; 387: 1561-1572.

15. Gurok MG, Yılmaz S, Temizkan A, et al. Levels of basophils and eosinophils are elevated while lymphocytes are reduced in patients with panic disorder compared to 
controls: a preliminary study. Psychiatry Clin Psychopharmacol 2019; 29: 315-319.

16. Hochman E, Weizman A, Valevski A, et al. Association between bipolar episodes and fluid and Electrolyte homeostasis: a retrospective longitudinal study. Bipolar Disord 2014; 16: 781-789.

17. Kalia M, Silva JC. Biomarkers of psychiatric diseases: Current status and future prospects. Metabolism 2015; 64 (3 Suppl 1): 11-15.

18. Karadağ F, Oral ET, Aran Yalçın F, et al. Young Mani Dercelendirme Ölçeğinin Türkiye'de geçerlilik ve güvenirliliği. Türk Psikiyatri Dergisi 2001; 13: 107-114.

19. Karataş KS, Bahçeci I, Telatar TG, Bahçeci B. Obsesif kompulsif bozuklukta plazma nötrofil jelatinaz ilişkili lipokalin ve hemogram düzeyleri ile hastalık şiddeti arasındaki ilişki. Anadolu Psikiyatri Derg 2020; 21: 585-591.

20. Karatas KS, Bahceci I, Telatar TG, et al. Relationship between disease and disease severity and semaphorin $5 \mathrm{~A}$ and hemogram level in obsessive-compulsive disorder. Nord J Psikiyatri 2021; 1-7.

21. Kirlioglu SS, Balcioglu YH, Kalelioglu T, et al. Comparison of the complete blood count-derived infl ammatory markers in bipolar patients with manic and mixed episodes. Bratisl Med J 2019; 120: 195-199.

22. Kulaksizoglu B, Kulaksizoglu S. Relationship between neutrophil/lymphocyte ratio with oxidative stress and psychopathology in patients with schizophrenia. Neuropsychiatr Dis Treat 2016; 12: 1999-2005.

23. Laziera K, Chowa EWC, AbdelMalika P, et al. Low platelet count in a 22q11 deletion syndrome subtype of schizophrenia. Schizophr Res 2001; 50: 177-180.

24. Matwiyoff GN, Prahl JD, Miller RJ, et al. Immune regulation of procalcitonin: A biomarker and mediator of infection. Inflamm Res 2012; 61: 401-409.

25. Mazza MG, Lucchi S, Tringali AGM, et al. Neutrophil/ lymphocyte ratio and platelet/lymphocyte ratio in mood disorders: a meta-analysis. Prog Neuro-Psychopharmacol Biol Psychiatry 2019; 84: 229-236.

26. McGrath J, Saha S, Chant D, Welham J. Schizophrenia: a concise overview of incidence, prevalence, and mortality. Epidemiol Rev 2008; 30: 67-76.

27. Mert DG, Terzi H. Mean platelet volume in bipolar disorder: the search for an ideal biomarker. Neuropsychiatr Dis Treat 2016; 12: 2057-2062

28. Miller BJ, Buckley P, Seabolt W, et al. Meta-analysis of cytokine alterations in schizophrenia: clinical status and antipsychotic effects. Biol Psychiatry 2011; 70: 663-671.

29. Miller BJ, Culpepper N, Rapaport MH. C-reactive protein levels in schizophrenia: a review and meta-analysis. Clin Schizophr Relat Psychoses 2014; 7: 223-230.

30. Moody G, Miller BJ. Total and differential white blood cell counts and hemodynamic parameters in first-episode psychosis. Psychiatry Res 2018; 260: 307-312.

31. Ng F, Berk M, Dean O, Bush Al. Oxidative stress in psychiatric disorders: evidence base and therapeutic implications. Int J Neuropsychopharmacol 2018; 11: 851-876.

32. Özdin S, Sarisoy G, Böke Ö. A comparison of the neutrophil-lymphocyte, platelet lymphocyte and monocyte-lymphocyte ratios in schizophrenia and bipolar disorder patients - a retrospective file review. Nord J Psychiatry 2017; 71: 509-512.

33. Pasko JA, Nicolson GC, Williams LJ, et al. Association of high-sensitivity C-reactive protein with de novodepression. Br J Psychiatry 2010; 197: 372-377.

34. Semiz M, Yildirim O, Canan F, et al. Elevated neutrophil/ lymphocyte ratio in patients with schizophrenia. Psychiatr Danub 2014; 26: 220-225.
35. Shehabi Y, Sterba M, Garret PM, et al. Procalcitonin algorithm in critically ill adults with undifferentiated infection or suspected sepsis. A randomized controlled trial. Am J Respir Crit Care Med 2014; 190: 1102-1110.

36. Smaga I, Niedzielska E, Gawlik M, et al. Oxidative stress as an etiological factor and a potential treatment target of psychiatric disorders. Part 2. Depression, anxiety, schizophrenia and autism Pharmacol Rep 2015; 67: 569-580.

37. Stein DJ, Scott KM, de Jonge P, Kessler RC. Epidemiology of anxiety disorders: from surveys to nosology and back. Dialogues Clin Neurosci 2017; 19: 127-136.

38. Sunbul EA, Sunbul M, Yanartas O, et al. Increased neutrophil/lymphocyte ratio in patients with depression is correlated with the severity of depression and cardiovascular risk factors. Psychiatry Investig 2016; 13: 121-126.

39. Tzura I, Barchela D, Izhakiana S, et al. Platelet distribution width: a novel prognostic marker in an internal medicine ward. J Community Hosp Intern Med Perspect 2019; 9: 464-470.

40. Vandeleur CL, Fassassi S, Castelao E, et al. Prevalence and correlates of DSM-5 major depressive and related disorders in the community. Psychiatry Res 2017; 250: 50-58.

41. Varun CN, Raju R, Venkataswamy MM, et al. Procalcitonin and $\mathrm{C}$-reactive protein as peripheral inflammatory markers in antipsychotic drug-free schizophrenia patients. Asian J Psychiatr 2018; 35: 11-14.

42. Walker C. Procalcitonin-guided antibiotic therapy duration in critically ill adults. AACN Adv Crit Care 2015; 26 : 99-106.

43. Wium-Andersen MK, Orsted DD, Nielsen SF, Nordestgaard BC. Elevated C-reactive protein levels, psychological distress and depression in 73,131 individuals. JAMA Psychiatry 2013; 70: 176-184.

44. Wysokiński A Szczepocka E. Red blood cell parameters in patients with acute schizophrenia, unipolar depression and bipolar disorder. Psychiatria Danubina 2018; 30 323-330.

45. Yazıcı MK, Demir B, Tanrıverdi N, et al. Hamilton Anksiyete Değerlendirme Ölçeği, değerlendiriciler arası güvenirlilik ve geçerlilik çalışması. Türk Psikiyatri Dergisi 1998; 9: 114-117. 